\title{
Delapan agenda pembangunan Provinsi NTT tahun 2013-2018 dalam agenda surat kabar
}

\author{
Eight development agenda of NTT Province 2013-2018 \\ in the newspaper agenda \\ Yohanes Museng Ola Buluamang \\ ${ }^{a}$ Badan Perencanaan Pembangunan Penelitian dan Pengembangan Daerah \\ Provinsi Nusa Tenggara Timur \\ E-mail: oyan_waibaloen@yahoo.co.id
}

Naskah Diterima : 20 Agustus 2018; Di-review : 22 Agustus 2018; Dimuat: 30 Agustus 2018

Copyright CFLOBAMORA 2019

\begin{abstract}
The implementation of the eight NTT Province development agendas (2013-2018) received attention in the daily news of Pos Kupang, Timor Ekspress and Victory News. The purpose of this study included identifying the quantity of news from the three newspapers, knowing the description of the news and testing the hypothesis of the different news coverage of three newspapers. The results of the analysis show that the most dominant news theme reported by Pos Kupang daily (71 news), Timor Ekspress (78 news) and Victory News (125 news) is the agenda of the development of populist economy and tourism. The description of the news by the Pos Kupang daily is dominated by neutral portrayals (109 news), Timor Ekspress is dominated by positive depictions (109 news) and Victory News is dominated by negative depictions (180 news). The results of the analysis show that there are significant differences in the news theme and news depiction of the NTT province's eight development agenda for 2013-2018 between the three newspapers. This confirms the importance of an issue that the media considers in determining the media agenda and the way the media express a reality.
\end{abstract}

Keywords : NTT Province Development Agenda; Newspapers; Media Agenda;neutral portrayals; positive depictions.

\section{Abstrak}

Pelaksanaan delapan agenda pembangunan Provinsi NTT (2013-2018) mendapat perhatian dalam pemberitaan harian Pos Kupang, Timor Ekspress dan Victory News. Tujuan kajian ini di antaranya untuk mengidentifikasi kuantitas pemberitaan ketiga surat kabar, mengetahui penggambaran beritanya dan menguji hipotesis perbedaan pemberitaan ketiga surat kabar tersebut. Hasil analisis menunjukkan bahwa tema berita yang paling dominan diberitakan harian Pos Kupang (71 berita), Timor Ekspress ( 78 berita) dan Victory News (125 berita) adalah agenda pembangunan ekonomi kerakyatan dan kepariwisataan. Penggambaran berita oleh harian Pos Kupang didominasi penggambaran yang netral (109 berita), Timor Ekspress didominasi penggambaran yang positif (109 berita) dan Victory News didominasi penggambaran yang negatif (180 berita). Hasil analisis menunjukkan bahwa terdapat perbedaan yang signifikan tema berita dan penggambaran berita delapan agenda pembangunan provinsi NTT tahun 2013-2018 antara ketiga surat kabar. Hal ini menegaskan tentang derajat pentingnya sebuah isu yang diperhatikan media dalam penentuan agenda media dan cara media membahasakan suatu realitas.

Keywords (Times New Roman, 9 bold ) : Agenda Pembangunan Provinsi NTT; Surat Kabar; Agenda Media; Penggambaran Netral; Penggamabaran Posositif.

\section{Pendahuluan}

Rencana Pembangunan Jangka Menengah Daerah (RPJMD) Provinsi Nusa Tenggara Timur tahun 2013-2018 memuat delapan agenda pembangunan yang merupakan penjabaran dari visi dan misi gubernur dan wakil gubernur terpilih. Delapam agenda pembangunan yang akan menjadi 
acuan dalam penyiapan kerangka kerja agenda pembangunan yaitu; pertama, meningkatkan pelayanan pendidikan dalam rangka terwujudnya mutu pendidikan, kepemudaan dan keolahragaan yang berdaya saing. Kedua, meningkatkan derajat dan kualitas kesehatan masyarakat melalui pelayanan yang dapat dijangkau seluruh masyarakat. Ketiga, memberdayakan ekonomi rakyat dan mengembangkan ekonomi kepariwisataan dengan mendorong pelaku ekonomi untuk mampu memanfaatkan keunggulan potensi lokal. Keempat, pembenahan sistem hukum dan reformasi birokrasi daerah. Kelima, mempercepat pembangunan infrastruktur yang berbasis tata ruang dan lingkungan hidup. Keenam, meningkatkan kualitas kehidupan keluarga, pemberdayaan perempuan, serta perlindungan dan kesejahteraan anak. Ketujuh, mempercepat pembangunan kelautan dan perikanan. Kedelapan, mempercepat penanggulangan kemiskinan, bencana dan pengembangan kawasan perbatasan (RPJMD Provinsi NTT, 2014).

Pada prinsipnya, delapan agenda pembangunan yang ditetapkan oleh gubernur dan wakil gubernur Provinsi NTT periode 2013-2018 didukung oleh good governance. Good governance mencirikan suatu organisasi yang berperan melaksanakan setiap kebijakan yang ditetapkan oleh policy makers dengan tujuan menyejahterakan masyarakat. Di dalam good governance terdapat juga kewajiban dari pemerintah untuk mendiseminasikan segala informasi pencapaian program pembangunan kepada masyarakat luas. Informasi pembangunan yang disampaikan kepada masyarakat dapat menghasilkan pemahaman dan feedback baik berupa masukan maupun kritikan terhadap pemerintah (Chatammalah, 2007).

Secara kuantitas dan kualitas, terdapat keberhasilan dan kegagalan dalam pencapaian delapan agenda pembangunan tersebut. Berbagai masalah yang muncul tersebut mendapat atensi atau sorotan media lokal dalam publikasinya. Pada konteks ini, media mengaktualisasikan fungsi mediator, sosialisasi, control atau mengawasi dan informasi, dan sebagainya terhadap jalannya suatu pemerintahan. Fungsi mediator oleh media ditunjukkan dengan kegiatan mediasi yang dijalankan apabila terjadi pro kontra atau konflik dalam pembangunan. Dalam menjalankan fungsi ini, media harus bersifat netral. Fungsi control media atau pers ditunjukkan dengan adanya pengawasan terhadap jalannya pembangunan. Sedangkan, fungsi informasi diwujudkan dengan menginformasikan berbagai kinerja pemerintah dalam pembangunan (Abrar, 2011; Wahyu, 2009).

Salah satu karya jurnalistik yang dihasilkan oleh surat kabar untuk menjalankan fungsi-fungsi di atas adalah berita. William C. Bleyer dalam Newspaper Writing and Editing, mendefinisikan berita sebagai sesuatu yang termassa yang dipilih oleh jurnalis untuk dimuat dalam surat kabar, karena menarik minat atau mempunyai makna bagi pembaca. Pada umumnya, berita yang dihasilkan oleh surat kabar memiliki berbagai jenis, seperti straight news report, depth reporting atau investigative reporting, comprehensive news dan feature story. Straight news report merupakan laporan langsung mengenai suatu peristiwa. Depth news report adalah laporan yang mendalam tentang suatu peristiwa. Comprehensive news merupakan laporan tentang fakta yang bersifat menyeluruh ditinjau dari berbagai aspek. Sedangkan, feature story adalah penyajian fakta dengan gaya penulisan yang menarik perhatian pembaca (Sumadiria, 2006).

Rumusan delapan agenda pembangunan dilatarbelakangi oleh berbagai isu strategis pembangunan yang dikaji secara mendalam, menjadi acuan dalam perencanaan dan pelaksanaan pembangunan. Pelaksanaan delapan agenda pembangunan mendapat perhatian surat kabar lokal, seperti; Pos Kupang, Timor Ekspress dan Victory News yang teraktualisasi dalam berbagai publikasi pemberitaan yang mencerminkan fungsi pers sebagai mediator, pengawas dan memberikan informasi. Laporan mengenai fakta yang dilaporkan secara langsung dan mendalam tentang pelaksanaan delapan agenda pembangunan Provinsi NTT 2013-2018 melalui surat kabar Pos Kupang, Timor Ekspress dan Victory News menggambarkan pencapaian keberhasilan dan permasalahan yang terjadi di lapangan.

Publikasi media lokal terkait fungsi control terhadap jalannya delapan agenda pembangunan Provinsi NTT 2013-2018, misalnya terlihat pada beberapa judul berita yang dipublikasi oleh ketiga surat kabar lokal. Berita Pos Kupang 14 November 2017, yang berjudul Waduh! Kemiskinan di NTT Ternyata pada Tingkat Seperti Ini mendeskripsikan tentang masih tingginya angka kemiskinan di NTT. Berita Victory News, 25 September 2017, yang berjudul Pariwisata NTT Terganjal Infrastruktur mendeskripsikan tentang pembangunan pariwisata di NTT, di satu sisi terus berkembang tapi di sisi lain terkendala dengan dukungan infrastruktur. Berita Timor Ekspress 8 Desember 2017, yang berjudul NTT Rangking Dua Nasional Destinasi Wisata mendeskripsikan tentang keunggulan potensi wisata yang dimiliki oleh NTT yang belum mendapat perhatian dari pemerintah daerah setempat.

Ketiga judul berita tersebut menunjukkan perbedaan agenda pembangunan yang dipublikasi oleh masing-masing surat kabar. Perbedaan judul dan agenda berita di atas mencirikan perbedaan agenda setting surat kabar terhadap suatu realitas yang akan dipublkasikan. Dalam perbedaan agenda setting, masing-masing surat kabar memperlihatkan bagaimana suatu realitas dinarasi dengan perbedaan pilihan kata, frase, dan kalimat sehingga membentuk keutuhan atau entitas berita yang berbeda. Dengan 
perbedaan agenda setting ini, surat kabar memiliki pengaruh secara signifikan terhadap cara pandang pembaca dalam memaknai realitas yang diberitakan (Cohen, 1963:13, McCombs dan Shaw, 1972) dalam (Kim et al., 2015). Agenda setting oleh ketiga surat kabar tentang pelaksanaan delapan agenda pembangunan provinsi NTT tidak sekedar mempublikasikan berbagai isu atau realitas tetapi menunjukkan bagaimana eksistensi surat kabar dalam menyikapi jalannya pembangunan di provinsi NTT. Dengan demikian, kontribusi utama ketiga surat kabar untuk proses politik dan pembangunan adalah agenda-setting yang menjadi faktor penentu dalam mengidentifikan isu-isu penting politik dan pembangunan suatu realitas atau objek pembangunan. Konsep agenda setting menunjukkan bahwa media massa berusaha mempublikasikan pikiran-pikiran banyak orang tentang fakta atau realitas yang menunjukkan adanya hubungan positif antara arti penting isu di dalam berita dengan isu-isu yang menonjol dalam pelaksanaan pembangunan atau berbagai peristiwa politik yang terjadi (Flaviu Rus, 2011).

Oleh karena itu, salah satu perspektif yang digunakan dalam mengkaji potret problem pelaksanaan delapan agenda pembangunan tersebut adalah komunikasi massa. Dengan pendekatan ini, kajian ini akan menggambarkan kuantitas pemberitaan surat kabar Pos Kupang, Timor Ekspress dan Victory News tentang pelaksanaan delapan agenda pembangunan Provinsi NTT tahun 20132018. Kajian terhadap liputan media atau media coverage tentang pelaksanaan delapan agenda pembangunan dapat mengerucut pada pilihan isu-isu strategis yang diperhatikan pada prioritas pembangunan selanjutnya. Hal ini merupakan suatu langkah antisipatif dalam perencanan pembangunan. Perumusan isu-isu strategis dapat mencermati fakta atau kondisi yang menggambarkan permasalahan pembangunan sebelumnya, sehingga meminimalisir adanya kesenjangan dalam pembangunan selanjutnya.

Berdasarkan uraian singkat sebelumnya, maka akan dilaksanakan suatu kajian pelaksanaan delapan agenda pembangunan Provinsi NTT (2013-2018). Batasan kajian ini difokuskan pada publikasi surat kabar lokal, di antaranya Pos Kupang, Timor Ekspress dan Victory News. Kajian terhadap media content menekankan pada kuantitas publikasi media lokal seputar pelaksanaan delapan agenda pembangunan tersebut.

Hasil kajian ini memiliki tiga tujuan, yakni untuk mengidentifikasi agenda pembangunan NTT yang dominan diberitakan oleh surat kabar Pos Kupang, Timor Ekspress dan Victory News, untuk mengetahui penggambaran agenda pembangunan Provinsi NTT oleh ketiga surat kabar dan untuk mengetahui perbedaan penggambaran ketiga surat kabar tentang delapan agenda pembangunan. Dengan demikian, kajian ini dapat bermanfaat dalam memperoleh data dan informasi yang berkaitan dengan masalahmasalah yang dominan dalam pencapaian delapan agenda pembangunan Provinsi NTT. Manfaat lainnya adalah untuk memperoleh data dan informasi yang berkaitan dengan agenda pembangunan yang menjadi prioritas dalam pelaksanaan pembangunan selanjutnya oleh pemerintah Provinsi NTT.

\section{Kerangka Teori}

Ada dua teori yang berkaitan dengan komunikasi massa atau studi media, yang dapat dijelaskan pada bagian ini, yakni agenda setting theory dan medium theory.

a) Agenda Setting Theory

Teori ini dicetuskan oleh McCombs dan Shaw pada tahun 1972. Teori ini menjelaskan bahwa penyusunan agenda membentuk gambaran atau isu yang penting dalam pikiran masyarakat. Penyusunan agenda terjadi karena media harus selektif dalam melaporkan berita. Saluran berita sebagai gate keeper informasi membuat pilihan tentang apa yang harus dilaporkan dan bagaimana melaporkannya (Littlejohn \& Foss, 2009).

Teori agenda setting menjelaskan hubungan antara penempatan isu-isu oleh media dengan isu-isu publik. Pengaturan agenda didasarkan pada pentingnya prioritas perhatian dalam isi media terhadap isu dan peristiwa (agenda media), memberitakan isu-isu yang menonjol dan pengetahuan sesuai agenda publik dan dampaknya pada opini publik. Selain itu, media juga dapat menjelaskan isu dan usulan kebijakan dari para politisi (D Rivera Rogel, et.al, 2013).

Ada dua tingkatan penyusunan agenda. Pertama, menentukan isu-isu umum yang dianggap penting. Kedua, menentukan bagian atau aspek dari isu-isu tersebut yang dianggap penting (Littlejohn \& Foss, 2009). Fungsi penentuan agenda media mengacu pada kemampuan media dengan liputan berita yang diulang-ulang untuk mengangkat pentingnya sebuah isu dalam benak publik (Severin \& Tankard, 2007). Menonjolnya isu mungkin menjadi faktor yang penting dalam penentuan agenda atau tidak (Zucker, 1978 dalam Severin \& Tankard, 2007). Ketiga, agenda setting tersebut dipengaruhi juga oleh ideologi media dan kepemilkan modal. Ini dapat menentukan arah dalam menyikapi peristiwa politik. Ideologi menandakan realitas yang berkaitan dengan kepentingan kelompok atau individu tertentu dan dengan bantuan framing meyakinkan pembaca terkait sikap media terhadap realitas tersebut (Farrukh dan Ahmad, 2015).

b) Medium Theory

Gagasan teori ini dimulai dengan penelitian McLuhan tentang bias sensorik yang beranggapan bahwa masing-masing medium memiliki tata bahasanya sendiri, dan menentukan hal-hal yang dipikirkan. McLuhan berpendapat bahwa medium 
beroperasi seperti bahasa (Littlejohn \& Foss, 2009). Medium adalah pesan karena membentuk dan mengendalikan bentuk hubungan dan tindakan manusia. Dalam praktiknya, media mempengaruhi individu-individu dalam masyarakat sekalipun terpisah dari content media yang disebarkan. Sebagai perpanjangan dari pikiran manusia, media mendominasi sejarah pikiran manusia. Artinya, segala sesuatu yang terjadi dan berpengaruh dalam periode sejarah kehidupan manusia ditentukan oleh media (Littlejohn \& Foss, 2009).

Salah satu riset yang berkaitan dengan kajian isi media berjudul Setting the Agenda for a Healthy Retail Environment: Content Analsis of US Newspaper Coverage of Tobacco Control Policies Affecting the Point of Sale, 2007-2014. Penelitian ini menggambarkan liputan berita tentang upaya pengendalian tembakau POS dan menilai hubungan antara karakteristik artikel, termasuk domain kebijakan, bingkai, sumber, lokalisasi dan bukti yang ada, dan arah pemberitaan. Hasil penelitian menunjukkan bahwa penggambaran berita mengenai cakupan POS memiliki perbedaan persentase dan arah pemberitaan yang berbeda untuk masing-masing cakupan POS (Myers et.al., 2016).

Riset lainnya yang berkaitan dengan perbedaan publikasi atau agenda pemberitaan oleh surat kabar berjudul Positioning Partai Demokrat Dalam Pemberitaan Surat Kabar. Riset ini menguji perbedaan publikasi tentang pencitraan partai Demokrat terkait kasus Hambalang oleh ketiga surat kabar nasional, yakni Kompas, Media Indonesia dan Jurnal Nasional. Hasil riset menunjukkan bahwa terdapat perbedaan pemberitaan yang signifikan tentang Positioning Partai Demokrat antara ketiga surat kabar tersebut (Buluamang, 2016).

\section{Metode}

Metode penelitian yang digunakan adalah deskriptif kuantitatif dengan pendekatan analisis isi kuantitatif. Analisis isi kuantitatif merupakan suatu teknik penelitian ilmiah yang ditujukan untuk mengetahui gambaran karakteristik isi dan menarik inferensi dari isi (Krippendorff K, 2004; Eriyanto, 2011; Kriyantono, 2010). Dengan pendekatan analisis isi media, kajian analisis isi media ini memusatkan pada konsep, dimensi, variabel, indikator dan kategori seperti pada tabel 1 .

Tabel 1. Konsep, Dimensi, Variabel, Indikator, Kategori dan Skala Pengukuran

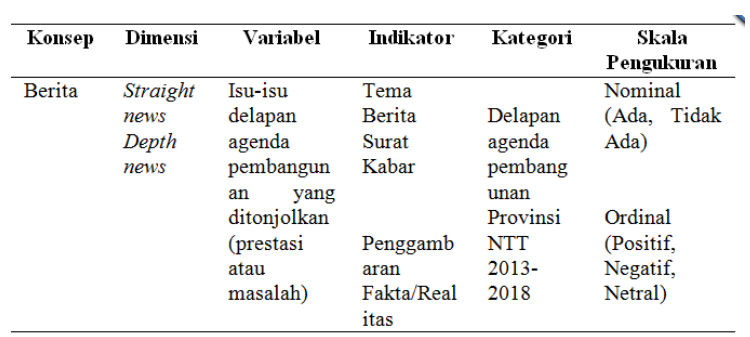

Unit analisis (tematik) yang digunakan adalah tema berita-berita tentang pelaksanaan delapan agenda pembangunan Provinsi NTT (2013-2018) selama bulan Januari-Juni tahun 2017 yang dipublikasi oleh Pos Kupang, Timor Ekspress dan Victory News. Penentuan unit analisis merujuk pada penggunaan unit sampling yang ditentukan dengan teknik purposive sampling. Instrumen penelitian adalah coding sheet (lembar coding) dengan teknik pengumpulan data menggunakan kliping. Uji validitas terhadap alat ukur menggunakan validitas muka dan isi. Hasil uji reabilitas alat ukur dengan formula Holsti terlihat pada tabel di bawah ini:

\begin{tabular}{|c|c|c|c|c|c|}
\hline $\begin{array}{c}\text { Variabel } \\
\text { Penelitian }\end{array}$ & $\begin{array}{l}\text { Jumlah } \\
\text { Berita }\end{array}$ & $\begin{array}{l}\text { Coding } \\
\text { yang Sama } \\
\text { (M) }\end{array}$ & $\begin{array}{c}\text { Reliabilit } \\
\text { as antar } \\
\text { coder } \\
2 M /(N 1+ \\
N 2) \\
\quad\end{array}$ & $\begin{array}{l}\text { Nilai Reabilitas } \\
\text { Minimun }\end{array}$ & Ket. \\
\hline $\begin{array}{l}\text { Tema } \\
\text { Berita }\end{array}$ & 15 & 12 & 0.8 & $0.8>0.70$ & Reliabel \\
\hline $\begin{array}{l}\text { Penggamb } \\
\text { aran } \\
\text { Berita }\end{array}$ & 15 & 11 & 0.73 & $0.73>0.70$ & Reliabel \\
\hline
\end{tabular}

Pendekataan ini menggunakan teknik analisis data statistik deskriptif, yakni distribusi frekuensi. Rumusnya: $\mathrm{N}=\frac{\mathrm{fx}}{\mathrm{N}} \mathrm{x} 100 \%$ (N: jumlah frekuensi dan Fx: frekuensi individu) (Bungin, 2009). Selain itu, digunakan juga analisis chi square (Sugiyono, 2010). Rumusnya sebagai berikut: $x^{2}=\frac{(O-E) 2}{E}$

\section{Hasil dan Pembahasan}

4.1. Delapan Agenda Pembangunan Provinsi NTT dalam Pemberitaan Ketiga Surat Kabar Lokal: Distribusi Frekuensi Tema dan Penggambaran Berita

Kajian analisis agenda atau isi media dilakukan terhadap berita-berita ketiga surat kabar. Jumlah berita ketiga surat kabar yang dijadikan unit analisis terdapat pada tabel 3 .

Tabel 3. Jumlah Edisi Unit Analisis Harian Pos Kupang, Timor Ekspress dan Victory News 


\begin{tabular}{|c|c|c|c|c|c|c|}
\hline \multirow{2}{*}{$\begin{array}{c}\text { Surat } \\
\text { Kabar }\end{array}$} & \multicolumn{6}{|c|}{ Periode Terbit } \\
\hline & Januari & Februari & Maret & $\begin{array}{c}\text { Apri } \\
1\end{array}$ & Mei & Juni \\
\hline $\begin{array}{l}\text { Harian Pos } \\
\text { Kupang }\end{array}$ & 23 edisi & 25 edisi & $\begin{array}{l}30 \\
\text { edisi }\end{array}$ & $\begin{array}{l}26 \\
\text { edisi }\end{array}$ & 28 edisi & $\begin{array}{l}24 \\
\text { edisi }\end{array}$ \\
\hline $\begin{array}{l}\text { Harian } \\
\text { Timor } \\
\text { Ekspress }\end{array}$ & 23 edisi & 25 edisi & $\begin{array}{l}30 \\
\text { edisi }\end{array}$ & $\begin{array}{l}27 \\
\text { edisi }\end{array}$ & 28 edisi & $\begin{array}{l}24 \\
\text { edisi }\end{array}$ \\
\hline $\begin{array}{l}\text { Harian } \\
\text { Victory } \\
\text { News }\end{array}$ & 25 edisi & 26 edisi & $\begin{array}{l}30 \\
\text { edisi }\end{array}$ & $\begin{array}{l}29 \\
\text { edisi }\end{array}$ & 29 edisi & $\begin{array}{l}25 \\
\text { edisi }\end{array}$ \\
\hline Total & 71 edisi & 76 edisi & $\begin{array}{l}90 \\
\text { edisi }\end{array}$ & $\begin{array}{l}82 \\
\text { edisi }\end{array}$ & 85 edisi & $\begin{array}{l}73 \\
\text { edisi }\end{array}$ \\
\hline
\end{tabular}

Dari jumlah edisi di atas, jumlah berita untuk masing-masing surat kabar sebagai berikut: Pos Kupang sebanyak 275 berita, Timor Ekspress sebanyak 272 berita dan Victory News sebanyak 454 berita. Berdasarkan jumlah unit analisis (sampling) di atas, dilakukan kajian analisis isi media. Hasil kajian agenda atau isi media ketiga surat kabar dengan menggunakan analisis isi media atau content media analysis dan dianalisis dengan perhitungan deskripsi frekuensi dapat dilihat pada tabel 1.4 di bawah ini: Tabel 4. Analisis Isi Media Delapan Agenda Pembangunan Provinsi NTT (2013-2018) pada Harian Pos Kupang, Timor Ekspress dan Victory News

Tabel 4. Prosentase hasil statistik

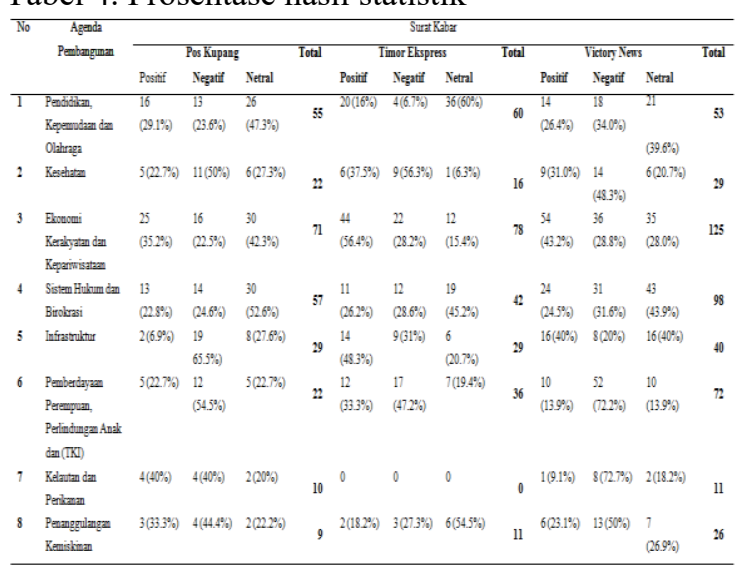

Tabel 1.4 menunjukkan beberapa point penting dari hasil penelitian di antaranya; pertama, agenda pembangunan Provinsi NTT (2013-2018) yang paling banyak dipublikasi harian Pos Kupang adalah agenda pembangunan ekonomi kerakyatan dan pariwisata sebanyak 71 berita, sedangkan agenda pembangunan yang paling sedikit dipublikasi oleh harian Pos Kupang adalah agenda pembangunan penanggulangan kemiskinan sebanyak 9 berita. Agenda pembangunan yang paling banyak dipublikasi oleh harian Timor Ekspress adalah agenda pembangunan ekonomi kerakyatan dan pariwisata sebanyak 78 berita. Sedangkan agenda pembangunan yang tidak pernah dipublikasi selama periode Januari-Juni 2017 adalah agenda pembangunan kelautan dan perikanan. Agenda pembangunan yang paling banyak dipublikasi oleh harian Victory News adalah agenda pembangunan ekonomi kerakyatan dan pariwisata sebanyak 125 berita, sedangkan agenda pembangunan yang paling sedikit dipublikasi adalah agenda pembangunan kelautan dan perikanan sebanyak 11 berita.

Kedua, agenda pembangunan yang paling banyak digambarkan secara positif oleh harian Pos Kupang adalah agenda pembangunan ekonomi kerakyatan dan kepariwisataan sebanyak 25 berita atau $35.2 \%$, secara negatif adalah agenda pembangunan infrastruktur sebanyak 19 berita atau $65.5 \%$, dan secara netral adalah agenda pembangunan ekonomi kerakyatan dan kepariwisataan sebanyak 30 berita atau $42.3 \%$, agenda pembangunan sistem hukum dan birokrasi sebanyak 30 berita atau 52.6\%. Sebaliknya, agenda pembangunan yang paling sedikit digambarkan secara positif oleh Pos Kupang adalah agenda pembangunan infrastruktur sebanyak 2 berita atau $6.9 \%$, secara negatif adalah agenda pembangunan kelautan dan perikanan sebanyak 4 berita atau $40 \%$ dan agenda pembangunan penanggulangan kemiskinan sebanyak $44.4 \%$, dan secara netral adalah agenda pembangunan kelautan dan perikanan sebanyak 2 berita atau 20\% dan agenda pembangunan penanggulangan kemiskinan sebanyak 2 berita atau $22.2 \%$.

Agenda pembangunan yang paling banyak digambarkan secara positif oleh Timor Ekspress adalah agenda pembangunan ekonomi kerakyatan dan kepariwisataan sebanyak 44 berita atau 56.4\%, secara negatif adalah agenda pembangunan pembangunan ekonomi kerakyatan dan kepariwisataan sebanyak 22 berita atau $28.2 \%$ dan secara netral adalah agenda pembangunan pendidikan, kepemudaaan dan olahraga sebanyak 36 berita atau $60 \%$. Sebaliknya, agenda pembangunan yang tidak pernah dipublikasikan oleh Timor Ekspress secara positif, negatif dan netral selama Januari-Juni 2017 adalah agenda pembangunan kelautan dan perikanan.

Agenda pembangunan yang paling banyak digambarkan secara positif oleh Victory News adalah agenda pembangunan ekonomi kerakyatan dan kepariwisataan sebanyak 54 berita atau $43.2 \%$, secara negatif adalah agenda pembangunan pemberdayaan perempuan dan penanggulangan anak (TKI) sebanyak 52 berita atau $72.2 \%$ dan secara netral adalah agenda pembangunan sistem hukum dan birokrasi sebanyak 43 berita atau 43.9\%. Sebaliknya, agenda pembangunan yang paling sedikit digambarkan secara positif oleh Victory News adalah agenda pembangunan kelautan dan perikanan sebanyak 1 berita atau 9.1\%, secara negatif adalah agenda pembangunan kelautan dan perikanan sebanyak 8 berita atau $72.7 \%$ dan agenda pembangunan infrastruktur sebanyak 8 berita atau $20 \%$, dan secara netral adalah agenda pembangunan kelautan dan perikanan sebanyak 2 berita atau $18.2 \%$. 
4.2. Delapan Agenda Pembangunan Provinsi NTT Tahun 2013-2018: Perbedaan Tema Berita dan Penggambaran Berita Antara Ketiga Surat Kabar Lokal

Pada bagian ini, ditampilkan perhitungan statistik tentang perbedaan tema pemberitaan dan penggambaran berita delapan agenda pembangunan provinsi NTT ketiga surat kabar.

a. Tema Berita Delapan Agenda Pembangunan Provinsi NTT Tahun 2013-2018

Hasil perhitungan statistik dengan analisis chi square $\left(\mathrm{X}^{2}\right)$ terhadap perbedaan tema berita delapan agenda pembangunan provinsi NTT ketiga surat kabar lokal dapat dilhat pada tabel 5 .

Berdasarkan tabel 5, maka dilakukan perhitungan lebih lanjut. Jadi, $d b=(8-1) \times(3-1)=$ 14. Menurut tabel nilai kritis, maka angka 14 memiliki nilai 23,685 . Dengan taraf signifikansinya $5 \%$, maka angka 38,70>23,685. Artinya, perbedaannya signifikan. Dari tabel di atas diketahui bahwa hasil perhitungan chi square $\left(\mathrm{X}^{2}\right)$ tema berita tentang delapan agenda pembangunan provinsi NTT tahun 2013-2018 menunjukkan perbedaan yang signifikan. Ini berarti pilihan atau penyeleksian terhadap delapan agenda pembangunan provinsi NTT tahun 2013-2018 selama bulan Januari-Juni 2018 oleh ketiga surat kabar berbeda-beda. Hal ini terlihat dari jumlah publikasi dan pilihan judul dan isi beritaberita tersebut yang dipublikasi pada setiap halaman ketiga surat kabar.

Tabel 5. Hasil Perhitungan Nilai Chi Square $\left(\mathrm{X}^{2}\right)$ Tema Pemberitaan Ketiga Surat Kabar

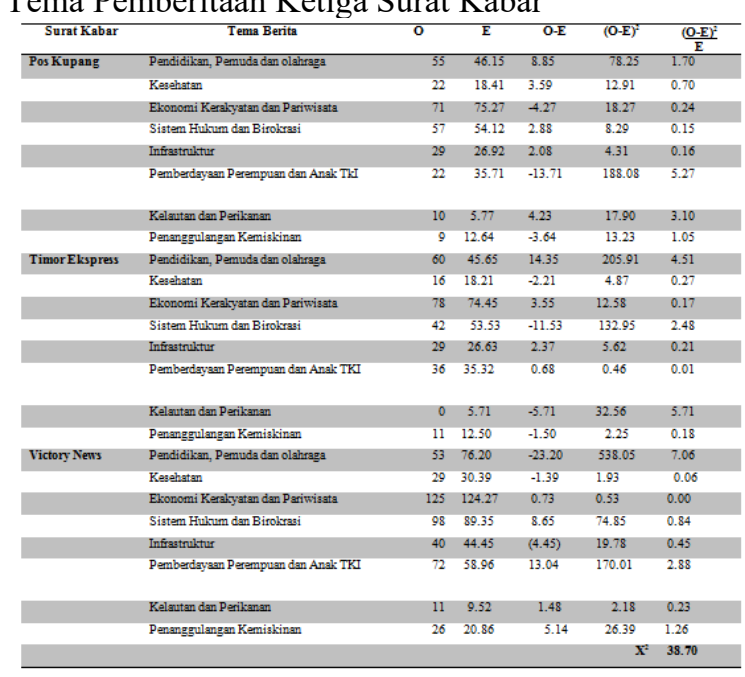

b. Penggambaran Berita Delapan Agenda Pembangunan Provinsi NTT Tahun 2013-2018

Hasil perhitungan statistik dengan analisis chi square $\left(\mathrm{X}^{2}\right)$ terhadap perbedaan penggambaran berita delapan agenda pembangunan provinsi NTT tahun 2013-2018 ketiga surat kabar lokal dapat dilihat pada tabel 6 .
Tabel 6. Hasil Perhitungan Nilai Chi Square $\left(\mathrm{X}^{2}\right)$ Penggambaran Pemberitaan 8 Agenda Pembangunan Ketiga Surat Kabar

\begin{tabular}{|c|c|c|c|c|c|c|}
\hline Surat Kabar & Penggambaran Berita & 0 & E & O-E & $(\mathbf{O}-\mathbf{E})^{2}$ & $\frac{(\mathbf{O}-\mathbf{E})^{2}}{\mathbf{E}}$ \\
\hline \multirow[t]{3}{*}{ Pos Kupang } & Positif & 73 & 86.81 & -13.81 & 190.80 & 2.20 \\
\hline & Negatif & 93 & 95.88 & -2.88 & 8.29 & 0.09 \\
\hline & Netral & 109 & 92.31 & 16.69 & 278.63 & 3.02 \\
\hline Timor & Positif & 109 & 85.87 & 23.13 & 535.18 & 6.23 \\
\hline \multicolumn{7}{|l|}{ Ekspress } \\
\hline & Negatif & 76 & 94.83 & -18.83 & 354.69 & 3.74 \\
\hline & Netral & 87 & 91.30 & -4.30 & 18.50 & 0.20 \\
\hline \multirow[t]{4}{*}{ Victory News } & Positif & 134 & 143.32 & -9.32 & 86.88 & 0.61 \\
\hline & Negatif & 180 & 158.29 & 21.71 & 471.42 & 2.98 \\
\hline & Netral & 140 & 152.39 & -12.39 & 153.55 & 1.01 \\
\hline & & & & & $x$ & 20.07 \\
\hline
\end{tabular}

Berdasarkan tabel di atas, maka dilakukan perhitungan lebih lanjut. Jadi, $d b=(3-1) \times(3-1)=4$. Berdasarkan tabel nilai kritis, maka angka 4 memiliki nilai 9,488 . Dengan taraf signfikansinya $5 \%$, maka nilai $\mathrm{X}^{2} \quad 20,07>9,488$. Artinya, perbedaannya signifikan. Hasil ini menunjukkan bahwa penggambaran berita tentang delapan agenda pembangunan provinsi NTT tahun 2013-2018 menunjukkan perbedaan yang signifikan. Ini berarti bahwa dalam narasi berita-berita seputar delapan agenda pembangunan provinsi NTT tahun 20132018, masing-masing surat kabar memiliki angle pemberitaan yang berbeda-beda. Selain itu, perbedaan penggambaran tersebut ditunjukkan juga dalam pelabelan terhadap fakta yang terjadi. Perbedaan penggambaran berita ditunjukkan juga dalam judul berita yang ditulis secara implicit dan eksplisit.

c. Pengujiaan Hipotesis

Rumusan hipotesis null $\left(\mathrm{H}_{0}\right)$ dan hipotesis alternatif $\left(\mathrm{H}_{\mathrm{a}}\right)$ berbunyi seperti di bawah ini:

Hipotesis 1

$\mathrm{H}_{01} \quad$ : Tidak ada perbedaan yang signifikan tema berita delapan agenda pembangunan provinsi NTT tahun 2013-2018 antara ketiga surat kabar (harian Pos Kupang, Timor Express dengan Victory News).

$\mathrm{H}_{\mathrm{a} 1} \quad$ : Ada perbedaan yang signfikan tema berita delapan agenda pembangunan provinsi NTT tahun 2013-2018 antara ketiga surat kabar (harian Pos Kupang, Timor Express dengan Victory News).

Hipotesis 2

$\mathrm{H}_{02} \quad$ : Tidak ada perbedaan yang signifikan penggambaran berita delapan agenda pembangunan provinsi NTT tahun 2013-2018 antara ketiga surat kabar (harian Pos Kupang, Timor Express dengan Victory News).

$\mathrm{H}_{\mathrm{a} 2} \quad$ : Ada perbedaan yang signifikan penggambaran berita delapan agenda pembangunan provinsi NTT tahun 2013-2018 antara ketiga surat kabar (harian Pos Kupang, Timor Express dengan Victory News).

Untuk menguji hipotesis perbedaan, dilakukan metode pengujian hipotesis dengan membandingkan nilai kritis dengan nilai $\mathrm{X}^{2}$. Jika nilai $\mathrm{X}^{2}$ lebih besar $(>)$ atau lebih besar sama dengan $(\geq)$ dari nilai kritis, maka $\mathrm{H}_{0}$ ditolak. Jika nilai $\mathrm{X}^{2}$ lebih kecil $(<)$ dari nilai kritis, maka $\mathrm{H}_{0}$ diterima. Hasil uji hipotesis 
terhadap hasil perhitungan nilai chi square $\left(\mathrm{X}^{2}\right)$ dapat dilihat pada tabel 7 di bawah ini:

Tabel 7. Hasil Uji Hipotesis

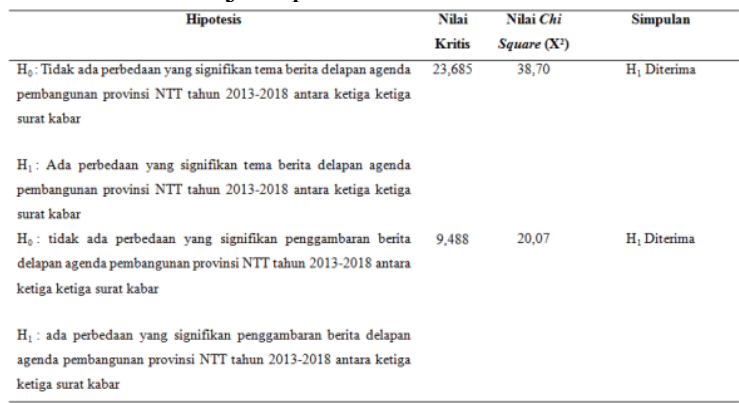

Dari tabel di atas, hasil pengujian hipotesis pertama menunjukkan bahwa nilai $\mathrm{X}^{2}$ untuk hipotesis pertama 38,70>23,685. Dengan demikian, $\mathrm{H}_{01}$ ditolak dan $\mathrm{H}_{\mathrm{a} 1}$ diterima. Ini berarti ada perbedaan yang signifikan tema berita delapan agenda pembangunan provinsi NTT tahun 2013-2018 antara ketiga surat kabar (harian Pos Kupang, Timor Express dengan Victory News). Sedangkan, hasil pengujian hipotesis kedua menunjukkan bahwa nilai $\mathrm{X}^{2}$ untuk hipotesis kedua 20,07>9,488. Dengan demikian, $\mathrm{H}_{02}$ ditolak dan $\mathrm{H}_{\mathrm{a} 2}$ diterima. Ini berarti ada perbedaan yang signifikan penggambaran berita delapan agenda pembangunan provinsi NTT tahun 2013-2018 antara ketiga surat kabar (harian Pos Kupang, Timor Express dengan Victory News).

\subsection{Memaknai Perbedaan Agenda Media}

Dari hasil penelitian ini dapat dijelaskan bahwa perbedaan kuantitas isi pemberitaan tentang delapan agenda pembangunan provinsi NTT tahun 2013-2018 oleh ketiga harian tersebut menegaskan penyusunan agenda terjadi karena adanya sikap selektif dalam melaporkan berita. Suatu isu yang menonjol mungkin menjadi faktor yang penting dalam penentuan agenda atau tidak (Zucker, 1978 dalam Severin \& Tankard, 2007). Saluran berita sebagai gate keeper informasi membuat pilihan tentang apa yang harus dilaporkan dan bagaimana melaporkannya (Littlejohn \& Foss, 2009). Selain itu, adanya perbedaan kuantitas isi pemberitaan ketiga surat kabar tentang delapan agenda pembangunan Provinsi NTT tahun 2013-2018 menunjukkan bahwa masing-masing surat kabar memiliki perbedaan derajat pentingnya isu-isu yang ingin dipublikasikan dari delapan agenda pembangunan Provinsi NTT tahun 2013-2018 dan aspek dari isu-isu tersebut (Littlejohn \& Foss, 2009). Penentuan agenda media tentang kedelapan agenda pembangunan Provinsi NTT tahun 2013-2018 mengacu pada kemampuan masing-masing surat kabar dengan liputan berita yang diulang-ulang untuk mengangkat pentingnya sebuah isu dalam benak publik (Littlejohn \& Foss, 2009). Dengan adanya perbedaan kuantitas tema berita delapan agenda pembangunan provinsi NTT tahun 2013-2018 oleh ketiga surat kabar, publik dihadapkan pada sikap selektif dalam memilih surat kabar yang dibaca, mengetahui dan memahami fakta yang terjadi. Perbedaan pilihan pembaca terhadap surat kabar menentukan juga gambaran pembaca terhadap realitas. Proses komunikasi seperti inilah yang kemudian menghadirkan agenda publik dalam memaknai agenda media.

Selain perbedaan kuantitas isi pesan, penggambaran realitas delapan agenda pembangunan provinsi NTT juga berbeda antara ketiga surat kabar. Letak perbedaan penggambaran yang ditunjukkan dengan pilihan penggunaan tata bahasa media ditegaskan dalam pandangan Mc Luhan bahwa masing-masing media memiliki tata bahasanya sendiri, dan menentukan hal-hal yang dipikirkan (Littlejohn \& Foss, 2009). Perbedaan dalam penyeleksian dan pemilihan fakta tentu berbeda dalam pilihan penggunaan bahasa. Meskipun demikian, terhadap fakta yang sama, masing-masing surat kabar menggunakan bahasa yang berbeda-beda pula untuk menggambarkan peristiwa atau fakta yang terjadi. Ini berarti setiap pesan yang disampaikan kepada publik menunjukkan identitas dan eksistensi ketiga surat kabar tersebut, sebagaimana ditekankan McLuhan bahwa setiap medium beroperasi seperti bahasa dan menunjukkan cara berbahasanya tersendiri (Littlejohn \& Foss, 2009). Oleh karena itu, untuk memahami penggambaran peristiwa oleh ketiga surat kabar tersebut, pemahaman terhadap bahasa jurnalistiknya membantu pembaca memahami fakta yang terjadi dan masing-masing surat kabar tersebut (West \& Turner, 2010).

\section{Kesimpulan}

Dari hasil penelitian di atas dapat disimpulkan beberapa point penting. Pertama, tema berita yang paling banyak (dominan) diberitakan oleh ketika surat kabar adalah agenda pembangunan ekonomi kerakyatan dan kepariwisataaan. Sedangkan, tema berita yang paling sedikit diberitakan oleh ketiga surat kabar adalah agenda pembangunan kelautan dan perikanan.

Kedua, penggambaran berita atau realitas tentang delapan agenda pembangunan oleh harian Pos Kupang, Timor Ekspress dan Victory News berbedabeda kuantitasnya untuk masing-masing agenda pembangunan. Secara umum, penggambaran berita atau realitas tentang delapan agenda pembangunan ketiga surat kabar antara lain; penggambaran yang negatif (349 berita), netral (336 berita) dan positif (316 berita). Oleh harian Pos Kupang didominasi oleh penggambaran yang netral (109 berita), oleh Timor Ekspress didominasi oleh penggambaran yang positif (109 berita) dan oleh Victory News didominasi oleh penggambaran yang negatif (180 berita). Penggambaran realitas atau berita yang netral oleh harian Pos Kupang paling banyak terdapat pada agenda pembangunan ekonomi kerakyatan dan kepariwisataan. Penggambaran realitas yang positif 
oleh harian Timor Ekspress paling banyak terdapat pada agenda pembangunan ekonomi kerakyatan dan kepariwisataan. Sedangkan, penggambaran realitas yang negatif oleh harian Victory News paling banyak terdapat pada agenda pemberdayaan perempuan dan perlindungan anak (TKI). Ketiga, hasil perhitungan analisis chi square $\left(\mathrm{X}^{2}\right)$ menunjukkan bahwa terdapat perbedaan yang signifikan tema berita dan penggambaran berita delapan agenda pembangunan provinsi NTT tahun 2013-2018 antara ketiga surat kabar.

Dari beberapa temuan dalam hasil penelitian, dapat disarankan beberapa hal. Pertama, ketiga surat kabar lebih gencar dan secara proporsional dalam mempublikasikan agenda-agenda pembangunan provinsi NTT. Kedua, ketiga surat kabar lebih intens dalam mengkritisi pelaksanaan agenda-agenda pembangunan di Provinsi NTT. Ketiga, pelaksanaan agenda-agenda pembangunan sebaiknya memerhatikan juga pemberitaan ketiga surat kabar dalam menjalankan fungsi kontrol.

\section{Ucapan Terima Kasih (Acknowledgments)}

Ucapan terima disampaikan kepada Kepala Badan Perencanaan Pembangunan, Penelitian dan Pengembangan Daerah Provinsi NTT, Kepala Bidang Penelitian dan Pengembangan Daerah BAPPELITBANGDA Provinsi NTT yang telah memercayakan dan memberi kesempatan kepada penulis untuk menyelesaikan tulisan ini. Ucapan terima kasih disampaikan kepada semua pihak yang telah membantu penulis menyelesaikan tulisan ini.

\section{Referensi}

Abrar, Ana Nadhya. (2011). Analisis Pers: Teori dan Praktik. Yogyakarta: Cahaya Atma Pustaka.

Adnjani, Made Dwi dan Mubarok. (2011). Analisis Pemberitaan tentang Unissula di Media Cetak (Analisis Isi Pemberitaan Harian Suara Merdeka dan Jawa Pos). Jurnal Ilmiah Komunikasi, 2 (1), 33-38.

Buluamang, Yohanes Museng Ola. (2016). Positioning Partai Demokrat Dalam Pemberitaan Surat Kabar. Jurnal Penelitian Pers dan Komunikasi Pembangunan, 20 (2), 109-119.

Bungin, Burhan. (2009). Metode Penelitian Kuantitatif. Jakarta: Kencana Prenada Media Grup.

Chatamallah, Maman. (2014). Opini Publik dan Kebijakan Pemerintah. Jurnal Komunikasi Mediator, 8 (2), 249-256.

Eriyanto. (2011). Analisis Isi: Pengantar Metodologi untuk Penelitian Ilmu Komunikasi dan IlmuIlmu Sosial Lainnya. Jakarta: Kencana Prenada Media Grup.
Farrukh, F dan Anmol Ahmad. (2015). Understanding Perpspective in a Media Text: Critical Discourse Analyses of Babar Sattar's Dangerous Contradictions. Journal of Research in Social Sciences, 3 (2).

Kim, J. Y., Kiousis, S., dan Xiang, Z. (2015). Agenda Building and Agenda Setting in Business: Corporate Reputation Attributes. Corporate Reputation Review, 18 (1), 25-36.

Kriyantono, Rahmat. (2010). Teknik Praktis Riset Komunikasi. Jakarta: Kencana Prenada Media Grup.

Littlejohn, Stephen W. dan Karen A. Foss. (2009). Teori Komunikasi. Jakarta: Salemba Humanika. Encylopedia of Theoty Communication. London: Sage Publications.

Myers, Alison E., et.al. (2016). Setting the Agenda for a Healthy Retail Environment: Content Analysis of US Newspaper Coverage of Tobacco Control Policies Affecting the Point of Sale, 2007-2014. BM Journal.

Rogel, D Rivera, et.al., (2013). Agenda Setting in Ecuadorian Media. Revista Latina de Comunicaion Social, 68, 529-544.

Rus, Flaviu C., et.al. (2011). Media Coverage of Politicians' Participations to Religious. Journal for the Study of Religions and Ideologies, 10 (29), 132-158.

Severin, Werner J. dan James W. Tankard. (2007). Teori Komunikasi: Sejarah, Metode, dan Terapan di Dalam Media Massa. Jakarta: Kencana Prenada Media Grup.

Sugiyono. (2013). Statistika untuk Penelitian. Bandung: Alfabeta.

Sumadiria, Haris AS. (2006). Jurnalistik Indonesia. Bandung: Simbiosa Rekatama Media.

West, Richard dan Lynn H. Turner. (2010). Introducing Communication Theory. Singapura: McGraw Hill.

Wibowo, Wahyu. (2009). Menuju Jurnalisme Beretika. Jakarta: Kompas.. 